\title{
Diet quality in patients with stroke
}

\author{
Jennifer L Dearborn, ${ }^{\oplus 1,2}$ Tehmina Khera, ${ }^{2}$ Meghan Peterson, ${ }^{2}$ Zartashia Shahab,, ${ }^{3}$ \\ Walter N Kernan ${ }^{3}$
}

To cite: Dearborn JL, Khera T, Peterson M, et al. Diet quality in patients with stroke. Stroke and Vascular Neurology 2019;4: e000224. doi:10.1136/svn2018-000224

- Additional material is published online only. To view please visit the journal online (http://dx.doi.org/10.1136/svn2018-000224).

Received 18 December 2018 Revised 27 February 2019 Accepted 11 March 2019 Published Online First 14 July 2019
Check for updates

(C) Author(s) (or their employer(s)) 2019. Re-use permitted under CC BY-NC. No commercial re-use. See rights and permissions. Published by BMJ.

${ }^{1}$ Department of Neurology, Beth Israel Deaconess Medical Center, Boston, Massachusetts, USA

${ }^{2}$ Department of Neurology, Yale University, New Haven, Connecticut, USA

${ }^{3}$ Department of Internal Medicine, Yale University School of Medicine, New Haven, Connecticut, USA

Correspondence to Dr Jennifer L Dearborn; jtomazos@bidmc.harvard.edu

\section{ABSTRACT}

Objective A healthy diet is associated with reduced risk for stroke, myocardial infarction, cancer and death. We examined the prevalence of a healthy diet in patients with a recent stroke or transient ischaemic attack (TIA). Methods We recruited a convenience sample of 95 patients with a recent ischaemic stroke or TIA. Using information from a 125-item Food Frequency Questionnaire, we calculated dietary quality and the percentage of patients meeting recommended daily intake (RDI) for common macronutrients and elements.

Results The mean age of patients was 66 years (SD: 16) and $46 \%$ were women. 39 patients (41\%) were classified as having a healthy diet $(35 \%$ of men and $48 \%$ of women). The majority of patients were within the RDI for carbohydrates $(56.8 \%)$, total fat $(61.1 \%)$, long-chain $\mathrm{n}-3$ fats $(68.4 \%)$, polyunsaturated fats $(79.0 \%)$ and protein $(96.8 \%)$. Very few patients consumed the recommended intake for sodium (25.3\%), and even fewer consumed the RDI for potassium (4.2\%), with the majority of patients consuming too much sodium and too little potassium. Conclusion We found that most patients with recent stroke or TIA were not following a healthy diet before their stroke event. For most patients, sodium intake was much above and potassium intake was much below RDI.

\section{INTRODUCTION}

Ischaemic stroke is a common and disabling condition affecting over 690000 US adults each year. ${ }^{1}$ Proven therapies mitigate the risk for recurrent stroke, but $5 \%$ of patients still suffer a recurrence each year. ${ }^{2}$ Therapies are needed to improve vascular health in patients with stroke, and one potential target is dietary quality. Improving dietary quality, through greater intakes of polyunsaturated fats, whole grains, fruits and vegetables, can lead to lower levels of insulin, glucose, triglycerides, blood pressure and inflammatory markers. ${ }^{34}$ Whether such dietary changes can prevent subsequent atherosclerosis-related outcomes, such as recurrent ischaemic stroke, remains to be shown in controlled clinical studies.

The potential value of an intervention to improve dietary quality after stroke depends largely on the prevalence of unhealthy eating among at-risk patients. To date, reliable data on dietary quality among stroke patients have been lacking and physicians do not routinely screen patients for dietary quality. ${ }^{5}$ In this study, we assessed and characterised premorbid dietary quality in a cohort of patients with recent stroke or transient ischaemic attack (TIA). We hypothesised that many of these patients would have poor premorbid dietary quality.

\section{METHODS}

\section{Study participants}

Eligibility criteria for the study were: English speaking, age $\geq 18$ years, diagnosis of ischaemic stroke or TIA and pass of a cognitive screen. ${ }^{6}$ Between April 2015 and February 2016, 113 patients were approached and 107 gave consent. We excluded seven patients with incomplete FFQs, two reporting implausible caloric intake and three with missing clinical data, leaving 95 patients.

\section{Dietary quality}

We administered a 125-item Food Frequency Questionnaire (FFQ), ${ }^{7}$ instructing patients to recall average diet in the 2 weeks before the stroke or TIA. We sampled the time period before the stroke because our goal was to identify acute patients who would be considered for future interventions and the stroke could affect current diet habits. We assumed that diet habits would be stable long term, such that problems with dietary quality before the stroke would be present afterwards.

We converted food and nutrient totals for each FFQ into daily intake by food category (eg, fruits, meats and sodium). These categories were used to derive the Alternative Health Eating Index (AHEI-2010), which was designed to predict risk of chronic disease, including cardiovascular disease and stroke $^{89}$ by including food groups that have been consistently associated with a lower risk of disease (online supplementary etable 1). All food categories are scored from 0 (unhealthy) to 10 (healthiest) with a total score ranging from 0 (no adherence) to 110 (perfect adherence).

\section{Classification of healthy diet}

Because AHEI-2010 is a continuous measure, there is no established cut-off to categorise diet as healthy. For our study, we used values 
Table 1 Participant features, overall and by Alternative Healthy Eating Index (AHEI) 2010 tertile

\begin{tabular}{|c|c|c|c|c|c|}
\hline \multirow[b]{3}{*}{ Feature } & \multirow[b]{2}{*}{ All } & \multicolumn{3}{|l|}{ AHEI tertile } & \multirow[b]{3}{*}{ P value* } \\
\hline & & $\leq 46.9$ & $46.9-56.5$ & $\geq 56.6$ & \\
\hline & $\mathrm{n}=95$ & $\mathrm{n}=32$ & $\mathrm{n}=32$ & $n=31$ & \\
\hline AHEl, range & $30.9-77.2$ & $30.9-46.8$ & $46.9-56.5$ & $56.6-77.2$ & \\
\hline Mean, SD & $52.7(10.1)$ & $42.6(3.9)$ & $50.9(2.8)$ & $65.0(5.4)$ & $<0.001$ \\
\hline Women & $44(46.3)$ & $13(40.6)$ & $17(53.1)$ & $14(45.2)$ & 0.61 \\
\hline Age, mean (SD) & $65.9(15.5)$ & $61.9(14.1)$ & $68.8(15.4)$ & $66.9(16.5)$ & 0.18 \\
\hline \multicolumn{6}{|l|}{ Education } \\
\hline Less than high school & $8(8.4)$ & $5(15.6)$ & $1(3.1)$ & $2(6.5)$ & 0.14 \\
\hline High school graduate & $30(31.6)$ & $13(40.6)$ & $13(40.1)$ & 4 (12.9) & \\
\hline More than high school & $57(60.0)$ & $14(43.8)$ & $18(56.3)$ & 25 (80.6) & \\
\hline \multicolumn{6}{|l|}{ Race } \\
\hline White & $75(79.0)$ & $22(68.7)$ & $27(84.4)$ & $26(83.9)$ & 0.33 \\
\hline Black & $15(15.8)$ & $6(18.8)$ & $5(15.6)$ & 4 (12.9) & \\
\hline Other & $5(5.2)$ & $4(12.5)$ & 0 & $1(3.2)$ & \\
\hline Body mass index $\left(\mathrm{kg} / \mathrm{m}^{2}\right) \dagger$ & $29.1(6.4)$ & $30.1(7.8)$ & $27.4(6.4)$ & $28.5(5.6)$ & 0.38 \\
\hline Prior stroke or TIA & $20(21.1)$ & 4 (12.5) & $10(31.3)$ & $6(19.4)$ & 0.18 \\
\hline Hypertension history & $66(69.5)$ & $24(75)$ & $20(62.5)$ & $22(71)$ & 0.54 \\
\hline Hyperlipidaemia history & $60(63.2)$ & $22(68.8)$ & $20(62.5)$ & $18(58.1)$ & 0.68 \\
\hline Diabetes & $25(26.3)$ & $23(71.2)$ & $23(71.2)$ & $24(77.4)$ & 0.85 \\
\hline Atrial fibrillation & $18(19.0)$ & $2(6.3)$ & 7 (21.9) & $9(29.0)$ & 0.06 \\
\hline Stroke (vs TIA) & $78(83)$ & $26(81.3)$ & $27(84.4)$ & $25(80.6)$ & 0.91 \\
\hline NIHSS (mean, SD) $\ddagger$ & $4(5)$ & $5(5)$ & $4(5)$ & $2(3)$ & 0.02 \\
\hline
\end{tabular}

Values are $n(\%)$ unless otherwise specified.

${ }^{*} \mathrm{P}$ value from ANOVA for continuous and $\chi^{2}$ for categorical variables.

tIncludes 92 participants with measured weight for BMI.

łIncludes 87 participants with NIHSS score.

AHEI, Alternative Health Eating Index; ANOVA, analysis of variance; BMI, body mass index; NIHSS, NIH Stroke Scale; TIA, transient ischaemic attack.

from an observational study of over 112000 healthy adults that found that in this population, patients in the fourth and fifth quintile of AHEI-2010 had a decreased risk of stroke as compared with the first quintile. ${ }^{8}$ We used the lower bound of the fourth quintile (55.3 for men and 51.4 for women) to define a healthy diet.

\section{Statistical analysis}

Participant characteristics were evaluated across tertiles of AHEI-2010. We examined the distribution of daily intake of common macronutrients and elements for men and women. We calculated the percentage of patients who consumed the recommended daily intake (RDI) of macronutrients and elements for men and women.

\section{RESULTS}

\section{Dietary quality}

Only one baseline characteristic, the NIH Stroke Scale Score, was significantly different across tertiles defined by the AHEI-2010. The score was 5 in the lowest AHEI tertile compared with 4 in the middle and 2 in the highest AHEI tertile ( $p$ value 0.02 by analysis of variance, table 1 ).
However, we observed several trends that were quantitatively important but that did not reach statistical significance. First, patients with the lowest dietary quality (first AHEI-2010 tertile) were on average younger, had less education and were more likely to be non-white race as compared with patients with higher dietary quality (ie, the second and third tertile). Second, patients with the lowest dietary quality had higher rates of hypertension and hyperlipidaemia as compared with patients with higher dietary quality. Third, diabetes rates were similar across dietary quality tertiles. Fourth, atrial fibrillation was more common in those with the highest dietary quality.

\section{Healthy diet}

Overall, 39 patients (41\%) were classified as having a healthy diet ( $35 \%$ of men and $48 \%$ of women).

\section{Recommended daily intakes}

Most patients were within the RDI for the macronutrients carbohydrates $(56.8 \%)$, total fat $(61.1 \%)$, long-chain n-3 fats $(68.4 \%)$, polyunsaturated fats $(79.0 \%)$ and protein $(96.8 \%)$ (table 2$)$. The minority of patients were within 
Table 2 Daily intake and per cent of patients meeting recommended daily intake (RDI) of common macronutrients, elements and food groups

\begin{tabular}{|c|c|c|c|c|c|c|c|c|}
\hline & \multicolumn{3}{|l|}{ Daily intake } & \multirow{2}{*}{$\begin{array}{l}\text { P } \\
\text { value* }^{*}\end{array}$} & \multirow{2}{*}{$\begin{array}{l}\text { Definition of RDI for each } \\
\text { macronutrient or element }\end{array}$} & \multicolumn{3}{|l|}{ RDI met } \\
\hline & All & Men & Women & & & All & Men & Women \\
\hline Total energy (kcal) & $1730(756)$ & $1855(796)$ & $1584(688)$ & 0.08 & & & & \\
\hline \multicolumn{9}{|l|}{ Macronutrients } \\
\hline $\begin{array}{l}\text { Carbohydrates } \\
\text { (g) }\end{array}$ & $210.8(94.8)$ & $223.5(101.5)$ & $196.1(85.0)$ & 0.16 & $45 \%-65 \%$ of total calories & $54(56.8)$ & 27 (52.9) & $27(61.4)$ \\
\hline Total fat (g) & $65.0(35.0)$ & $69.7(37.0)$ & $59.7(32.1)$ & 0.17 & $20 \%-35 \%$ of total calories & $58(61.1)$ & $31(60.8)$ & $27(61.4)$ \\
\hline Long-chain n-3 fats (g) & $1.6(0.9)$ & $1.6(0.9)$ & $1.6(0.9)$ & 0.98 & $0.6 \%-1.2 \%$ of total calories & $65(68.4)$ & $35(68.6)$ & $30(68.2)$ \\
\hline Polyunsaturated fat (g) & $15.0(8.0)$ & $15.8(8.2)$ & $13.9(7.8)$ & 0.25 & $5 \%-10 \%$ of total calories & $75(79.0)$ & 39 (76.5) & $36(81.8)$ \\
\hline Protein $(\mathrm{g})$ & $72.4(35.7)$ & $79.0(36.3)$ & $64.8(54.5)$ & 0.05 & $10 \%-35 \%$ of total calories & $92(96.8)$ & $49(96.1)$ & $43(97.7)$ \\
\hline Saturated fat (g) & $20.8(12.2)$ & $22.0(13.2)$ & $19.4(10.7)$ & 0.31 & & & & \\
\hline Trans fat (g) & $2.2(1.4)$ & $2.4(1.6)$ & $1.9(1.1)$ & 0.10 & & & & \\
\hline \multicolumn{9}{|l|}{ Elements } \\
\hline Sodium (g) & $2.8(1.4)$ & $3.1(1.4)$ & $2.5(1.2)$ & 0.03 & $1.5-2.3 \mathrm{~g} /$ day & $24(25.3)$ & $15(29.4)$ & $9(20.5)$ \\
\hline Potassium (g) & $2.5(1.0)$ & $2.7(1.1)$ & $2.4(1.0)$ & 0.17 & $\geq 4.7 \mathrm{~g} /$ day & $4(4.2)$ & $3(5.9)$ & $1(2.3)$ \\
\hline \multicolumn{9}{|l|}{ Food groups and fibre } \\
\hline Fibre (g) & $17.2(7.3)$ & $18.0(7.5)$ & $16.3(7.1)$ & 0.26 & & & & \\
\hline Fruit (servings) & $2.3(1.6)$ & $2.2(1.6)$ & $2.3(1.7)$ & 0.70 & & & & \\
\hline Vegetables (servings) & $2.3(2.0)$ & $2.1(1.4)$ & $2.4(2.5)$ & 0.45 & & & & \\
\hline Fish (servings) & $0.2(0.3)$ & $0.2(0.3)$ & $0.2(0.3)$ & 0.91 & & & & \\
\hline Nuts (servings) & $0.3(0.4)$ & $0.3(0.5)$ & $0.2(0.2)$ & 0.05 & & & & \\
\hline Meat (servings) & $0.9(0.8)$ & $1.0(0.8)$ & $0.8(0.8)$ & 0.13 & & & & \\
\hline Dairy (servings) & $0.6(0.6)$ & $0.6(0.5)$ & $0.6(0.6)$ & 0.67 & & & & \\
\hline Whole grain (servings) & $0.6(0.6)$ & $0.6(0.6)$ & $0.5(0.6)$ & 0.24 & & & & \\
\hline \multicolumn{9}{|l|}{ Beverages } \\
\hline Alcohol (g) & $6.8(11.7)$ & $7.9(13.0)$ & $5.4(9.9)$ & 0.32 & & & & \\
\hline SSB (servings) & $1.1(1.6)$ & $1.3(2.0)$ & $0.8(0.9)$ & 0.16 & & & & \\
\hline
\end{tabular}

Values for daily intake represent mean (SD) for all participants $(n=95)$; men $(n=51)$ and women $(n=44)$.

$\mathrm{RDI}$ is defined from from: https://ods.od.nih.gov/Health_Information/Dietary_Reference_Intakes.asp.

$\mathrm{RDI}$ met is displayed as $\mathrm{n}(\%)$.

${ }^{*} \mathrm{P}$ value represents two-sided t-test of differences of means between men and women.

SSB, sugar-sweetened beverages.

the RDI for the elements sodium $(25.3 \%, \mathrm{n}=24)$ and potassium $(4.2 \%, \mathrm{n}=4)$, with average sodium intake being higher and potassium intake being lower than recommended (table 2 ). The mean sodium intake was $2.8 \mathrm{~g} /$ day (SD: 1.4), and the mean potassium intake was $2.5 \mathrm{~g} /$ day (SD 4.2). Men consumed a significantly higher amount of protein and sodium as compared with women (table 2).

\section{DISCUSSION}

In this study, we found that overall dietary quality was poor, with most patients not following a healthy diet before the stroke event. Second, we found that most patients had high sodium and low potassium intake, which is closely associated with hypertension, the major risk factor for stroke. Our findings suggest that among hospitalised patients who had a stroke, premorbid dietary quality is poor with particular problems related to sodium and potassium.

Only one prior study examined dietary quality among patients with a recent stroke. This study included 73 participants from South Korea with recent stroke and used an 85-item FFQ to calculate diet quality, using the diet quality index, in the year preceding the stroke. ${ }^{10}$ In agreement with our findings in a US population, the authors found that, overall, patients with recent stroke had low diet quality, high sodium consumption and low potassium consumption preceding their ischaemic event.

Our results suggest that dietary quality in patients with recent stroke and TIA is similar to dietary quality in the US adult population. A large cohort study including women age 30-55 years and men age 40-75 years reported a mean score AHEI-2010 score of 48 (SD: 11) in women and 52 (SD: 12) in men. ${ }^{9}$ In this cohort study, $40 \%$ of participants consumed a healthy diet, ${ }^{9}$ similar to the $41 \%$ rate observed in this study of participants with stroke or TIA.

We asked patients to recall their diet pattern during the 2 weeks prior to their stroke, but we believe the findings likely reflect diet quality after stroke. Without intense counselling, patients rarely make substantial changes in 
their diet. If we are correct, our findings may have implications for secondary stroke prevention. Improved diet quality, including reduced sodium intake and increased potassium intake, may ameliorate stroke risk factors such as high blood pressure, dyslipidaemia, glucose metabolism and vascular inflammation. ${ }^{11} 12$ Our work suggests that counselling patients who had a stroke on a dietary pattern that emphasises low sodium and high potassium, such as the Dietary Approaches to Stop Hypertension diet, may positively impact the blood pressure of patients poststroke. $^{13}$

A limitation of the study is that it was performed at a single centre, which may limit generalisability, as it is known that diet varies by region. ${ }^{14}$ In addition, we recruited a convenience sample, although we have no reason to believe that enrolled patients differ from other patients admitted to the hospital with stroke. We report dietary information on a relatively small sample; however, we also note that the distribution of scores (SD: 10.1) was similar to the distribution of scores in a large general population sample (SD: 11 in 71495 women and SD: 12 in $41029 \mathrm{men}^{9}$ ), suggesting that our sample size was adequate to represent the full distribution of dietary intake. Dietary information was collected by self-report, which is a subjective measure. The limitations to the use of FFQs in observational research apply to our measure of dietary quality. FFQs can results in random measurement errors or systemic biases in patient reporting due to personality or disease-related factors. ${ }^{15}$ Additionally, this study was only able to capture diet in patients who were able to complete an FFQ unassisted, which eliminated those with the most severe strokes, aphasia or other cognitive deficits. This group of patients severely affected by the stroke represents an ongoing challenge to adequately measure dietary practices retrospectively and prospectively.

Average dietary quality is poor in patients with a recent stroke or TIA and could potentially be improved by nutritional counselling and interventions for behavioural change. Although it remains to be shown that dietary change reduces risk for recurrent vascular events or improves functional outcomes, it is known that dietary change can improve stroke risk factors such as blood pressure, lipid concentrations and glucose tolerance. ${ }^{13} 16$ Clinical trials are warranted to test dietary improvement for secondary prevention.

Contributors JLD: study design, primary authorship of manuscript, statistical analysis, interpretation of data and approval of final manuscript. No disclosures. TK: data collection and approval of final manuscript. No disclosures. MP: data collection and approval of final manuscript. No disclosures. ZS: data collection and approval of final manuscript. No disclosures. WNK: study design, data interpretation, manuscript revision and approval of final manuscript. No disclosures.

Funding Dr. Dearborn received funding from the Robert E. Leet and Clara Guthrie Patterson Trust Mentored Research Award, Bank of America, N.A., Trustee.

Competing interests None declared.

Patient consent for publication Not required.

Provenance and peer review Not commissioned; externally peer reviewed.

Open access This is an open access article distributed in accordance with the Creative Commons Attribution Non Commercial (CC BY-NC 4.0) license, which permits others to distribute, remix, adapt, build upon this work non-commercially, and license their derivative works on different terms, provided the original work is properly cited, appropriate credit is given, any changes made indicated, and the use is non-commercial. See: http://creativecommons.org/licenses/by-nc/4.0/.

\section{REFERENCES}

1. As G, Mozaffarian D, Roger VL, et al. Heart disease and stroke statistics - 2014 update: a report from the American Heart Association. Circulation 2013.

2. Kernan WN, Ovbiagele B, Black HR, et al. Guidelines for the prevention of stroke in patients with stroke and transient ischemic attack: a guideline for healthcare professionals from the American Heart Association/American Stroke Association. Stroke 2014;45:2160-236.

3. Lutsey PL, Steffen LM, Stevens J. Dietary intake and the development of the metabolic syndrome: the Atherosclerosis Risk in Communities study. Circulation 2008;117:754-61.

4. Nettleton JA, Schulze MB, Jiang R, et al. A priori-defined dietary patterns and markers of cardiovascular disease risk in the Multi-Ethnic Study of Atherosclerosis (MESA). Am J Clin Nutr 2008;88:185-94.

5. Smith AW, Borowski LA, Liu B, et al. U.S. primary care physicians diet-, physical activity-, and weight-related care of adult patients. Am J Prev Med 2011;41:33-42.

6. Callahan CM, Unverzagt FW, Hui SL, et al. Six-item screener to identify cognitive impairment among potential subjects for clinical research. Med Care 2002;40:771-81.

7. Patterson RE, Kristal AR, Tinker LF, et al. Measurement characteristics of the Women's Health Initiative food frequency questionnaire. Ann Epidemiol 1999:9:178-87.

8. McCullough ML, Feskanich D, Stampfer MJ, et al. Diet quality and major chronic disease risk in men and women: moving toward improved dietary guidance. Am J Clin Nutr 2002;76:1261-71.

9. Chiuve SE, Fung TT, Rimm EB, et al. Alternative dietary indices both strongly predict risk of chronic disease. J Nutr 2012;142:1009-18.

10. Lim H, Choue R. Dietary pattern, nutritional density, and dietary quality were low in patients with cerebral infarction in Korea. Nutr Res 2011;31:601-7.

11. He J, Ogden LG, Vupputuri S, et al. Dietary sodium intake and subsequent risk of cardiovascular disease in overweight adults. JAMA 1999;282:2027-34.

12. Bazzano LA, He J, Ogden LG, et al. Dietary potassium intake and risk of stroke in US men and women: National Health and Nutrition Examination Survey I epidemiologic follow-up study. Stroke 2001;32:1473-80

13. Sacks FM, Svetkey LP, Vollmer WM, et al. Effects on blood pressure of reduced dietary sodium and the Dietary Approaches to Stop Hypertension (DASH) Diet. N Engl J Med Overseas Ed 2001;344:3-10.

14. Howard VJ, Cushman M, Pulley L, et al. The reasons for geographic and racial differences in stroke study: objectives and design. Neuroepidemiology 2005;25:135-43.

15. Byers T. Food frequency dietary assessment: how bad is good enough? Am J Epidemiol 2001;154:1087-8.

16. Doménech M, Roman P, Lapetra J, et al. Mediterranean diet reduces 24-hour ambulatory blood pressure, blood glucose, and lipids: oneyear randomized, clinical trial. Hypertension 2014;64:69-76. 